\title{
Effect of Ambient UV-B on Stomatal Density, Conductance and Isotope Discrimination in Four Field Grown Soybean [Glycine max (L.) Merr.] Isolines
}

\author{
Dennis C. Gitz III ${ }^{{ }^{*}}$, Steven J. Britz ${ }^{2}$, Joseph H. Sullivan ${ }^{3}$ \\ ${ }^{1}$ USDA-ARS ${ }^{\#}$, Cropping Systems Research Laboratory, Lubbock, USA; ${ }^{2}$ USDA-ARS, Food Components and Health Laboratory, \\ Beltsville, USA; ${ }^{3}$ Department of PLSA, College of Agriculture and Natural Resources, University of Maryland, College Park, \\ USA. \\ Email: *dennis.gitz@ars.usda.gov
}

Received October $30^{\text {th }}, 2013$; revised December $3^{\text {rd }}, 2013$; accepted December $13^{\text {th }}, 2013$

Copyright (C) 2013 Dennis C. Gitz III et al. This is an open access article distributed under the Creative Commons Attribution License, which permits unrestricted use, distribution, and reproduction in any medium, provided the original work is properly cited.

\begin{abstract}
An experiment was designed to test whether ambient levels of UV-B radiation affect stomatal development, decrease stomatal density, and lead to increased water-use efficiency (WUE). Soybean [Glycine max (L.) Merr.] isolines with different stomatal distribution and flavonol expression patterns were field grown under shelters that either transmitted or blocked solar UV-B. All isolines exposed to solar UV-B accumulated higher concentrations of UV-screening phenolic pigments but other responses were isoline dependent. Solar UV-B decreased stomatal density and conductance in isolines expressing a unique branched kaempferol triglycoside. Decreased stomatal density was associated with increased season-long WUE and decreased internal $\mathrm{CO}_{2}$ concentration of leaf (estimated by $\delta^{13} \mathrm{C}$ discrimination). We concluded that photomorphogenic responses to UV-B affected stomatal density and WUE in field grown soybean; but that the magnitude and direction of these response were associated with isogenic pleiotropic differences in stomatal distribution and pigment expression. UV-B radiation had no effect on biomass accumulation or yield in a cultivar expressing only trace levels of kaempferol suggesting that flavonol expression is not prerequisite to UV-B tolerance.
\end{abstract}

Keywords: Soybean; UV-B; Drought Stress; Water Use Efficiency; Isotope Discrimination; Photomorphogenesis

\section{Introduction}

Through the last quarter of the 1900 s, there was a considerable concern that depletion of stratospheric ozone by anthropogenic and natural halogens would result in increased UV-B $(280-315 \mathrm{~nm})$ in the terrestrial solar spectral distribution $[1,2]$. Though stratospheric ozone

\footnotetext{
"Corresponding author.

\#The US Department of Agriculture (USDA) prohibits discrimination in all its programs and activities on the basis of race, color, national origin, age disability, and where applicable, sex, marital status, familial status, parental status, religion, sexual orientation, genetic information, political beliefs, reprisal, or because all or part of an individual's income is derived from any public assistance program. (Not all prohibited bases apply to all programs.) Persons with disabilities who required alternative means for communication of program information (Braille, large print, audiotape, etc.) should contact USDA's TARGET Center at (202) 720-2600 (voice and TDD). To file a complaint of discrimination, write to USDA, Office of Civil Rights, 1400 Independence Avenue, S.W., Washington, D.C. 20250-9410, or call (800) 795-3272 (voice) or (202) 720-6382 (TDD). USDA is an equal opportunity provider and employer.
}

depletion is expected to peak in this decade, recovery of stratospheric ozone concentrations remains uncertain given current climate change scenarios [3]. For such reasons, research into the effects of terrestrial UV-B has resulted in a considerable body of literature.

Terrestrial UV varies with latitude, elevation and season. The UV-B waveband is a small fraction of the total terrestrial solar spectrum, but elicits disproportionally large responses from plants. It is generally accepted that UV-B affects both the physiology and development of plants [4,5]. Interest in UV-B effects on plants has not been limited to plant stress and crop yield effects [6], but includes changes in ecosystem composition [3,7-9].

The effects of UV-B on plants have been and continue to be summarized in periodic reviews (e.g. [3-13]). In general, plant responses to UV-B can be arbitrarily divided into two classes, photomorphogenic and stress responses. Stress responses are typically defined as those resulting from applied or increased levels of a stressor as 
compared to a plant's "normal" or optimal growing conditions and are often associated with damage leading to reductions in metabolism, growth, and development [14]. An exception to this view is the case of crop plants, where stress effects are often extended to include decreases in crop yield whether they result from stress or photomorphogenic responses [6]. Photomorphogenic responses resulting in altered architecture or chemical composition are usually thought to be adaptive responses of plant development to light, or perhaps more accurately the radiation micro-environment through non-damaging signal perception pathways. This is especially true with regard to UV-B plant responses that can be described as photomorphogenic rather than damage responses [15].

Such UV-B photomorphogenic responses have been hypothesized to confer advantages under conditions associated with high-light environments such as water stress $[13,16]$. Alteration in stomatal conductance in the absence of reduced assimilation could enhance instantaneous WUE or increase the stomatal limitation to photosynthesis. This has been demonstrated in several cases and could lead to improved drought tolerance [17-23]. Variability exists in such responsiveness to UV-B, however. For example, Nogués and Baker found no effect of UV-B on the drought response in three Mediterranean species grown under enhanced UV-B radiation before and during the imposition of drought treatments [24]. Reductions in transpiration, conductance, and $\mathrm{C}_{\mathrm{i}}$ with UV-B have been reported in soybean, but altered carbon isotope ratios have also been attributed to disrupted photosynthetic metabolism processes [25].

In soybean, drought tolerance has been shown to be correlated with UV-B radiation levels in the field [17]. Likewise, instantaneous water use efficiency (WUE) is affected by supplemental UV-B in soybean and rice [18, 20]. Current ambient levels of UV radiation have been shown to modify leaf morphology and gas exchange in Populus [26]. UV-B radiation has the potential to affect the stomatal density in pea [22], although it was suggested that there was little potential for this to result in altered gas exchange characteristics. Soybean grown under UV-B simulating $25 \%$ ozone depletion decreased stomatal density and led to increased instantaneous and long-term WUE in glasshouse grown soybean [27].

Previously, we reported that soybean cultivars exhibited increased WUE with supplemental UV-B in glasshouse studies [27]. This response was manifested through changes in stomatal development [27]. Since extending such results from chamber or glasshouse experiments to predict responses in field settings is fraught with assumption [28], we investigated whether similar results would be found in field settings. In addition to expanding upon previous studies, soybean was used rather than other agronomically important species be- cause unique isolines were available that differed in both stomatal development and flavonol expression (Table 1). The purpose of this study was to investigate whether responses to ambient levels of UV-B radiation would induce morphological changes, specifically reduced stomatal density, which might lead to enhanced WUE in field grown soybean.

\section{Methods}

\subsection{Plant Material, Growth Conditions, and Irradiation Treatments}

Soybean (Glycine max), OX921, OX922, OX941 and OX942 were glasshouse grown for two weeks and transplanted into field plots under eight open-ended $5.5 \times 5.2$ $\times 2.3 \mathrm{~m}(1 \times \mathrm{w} \times \mathrm{h})$ hoop shelters constructed of steel tubing and oriented east-west along the major axis of the shelters (Figure 1). Four shelters were covered with $0.762 \mathrm{~mm}$ (3 mil) Teflon ${ }^{\circledR}$ fluroethylene propylene (FEP, DuPont, Circleville, OH, USA) (solar UV transparent) and the other four were covered with $0.127 \mathrm{~mm}(5 \mathrm{mil})$ polyester (excludes UV-B below $315 \mathrm{~nm}$ ) film spectrally equivalent to Mylar ${ }^{\mathbb{B}}$ type $\mathrm{D}$ plastic ${ }^{1}$.

The polyester film was changed twice during the course of the experiment while the Teflon was left in place throughout the experiment. The spectral distribution (Figure 2) of the radiation under the shelters at canopy height was characterized at $1 \mathrm{~nm}$ intervals with an OL754 spectroradiometer which had been calibrated with a OL752-10 NIST traceable $200 \mathrm{~W}$ tungsten-halogen standard lamp (Optronic Laboratories, Inc., Orlando, FL).

Radiation under the shelters was checked periodically with a broadband radiometer (Model 3D UV Meter, Solar Light Co. Inc., Philadelphia). The plots were irrigated throughout the growing season with water pumped from a nearby creek and delivered through a soaker hose. Soil moisture in each plot was monitored with five gypsum blocks (Model 5201, Soilmoisture Equipment, Santa Barbara, CA) buried at $25 \mathrm{~cm}$ depth. Irrigation frequency and duration was varied to maintain soil moisture throughout the season and to minimize soil moisture variation between plots.

\subsection{Leaf Morphology}

Shortly after anthesis fully expanded leaves from near the top of the canopy (the fourth leaf from the apex $>1$ $\mathrm{cm}$ in length) from 10 separate plants in each isoline were selected from along the middle $1.8 \mathrm{~m}$ section of each row.

\footnotetext{
${ }^{1}$ Mention of trade names or commercial products in this article is solely for the purpose of providing specific information and does not imply recommendation or endorsement by the US Department of Agriculture.
} 


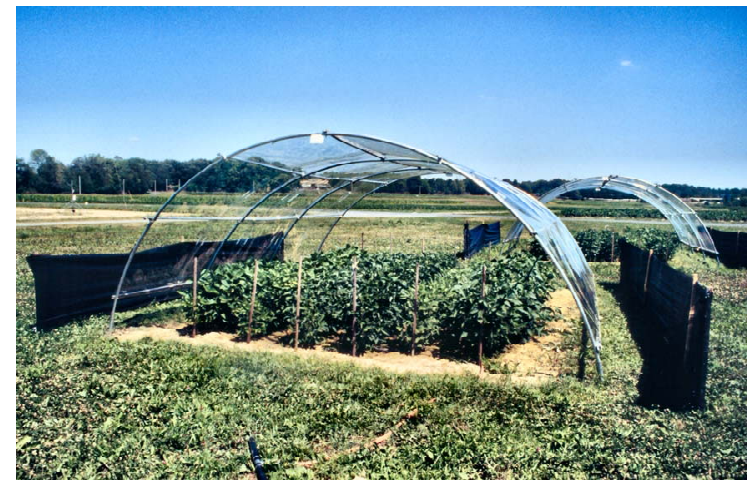

Figure 1. Hoop-house exclusion shelter and field plot.

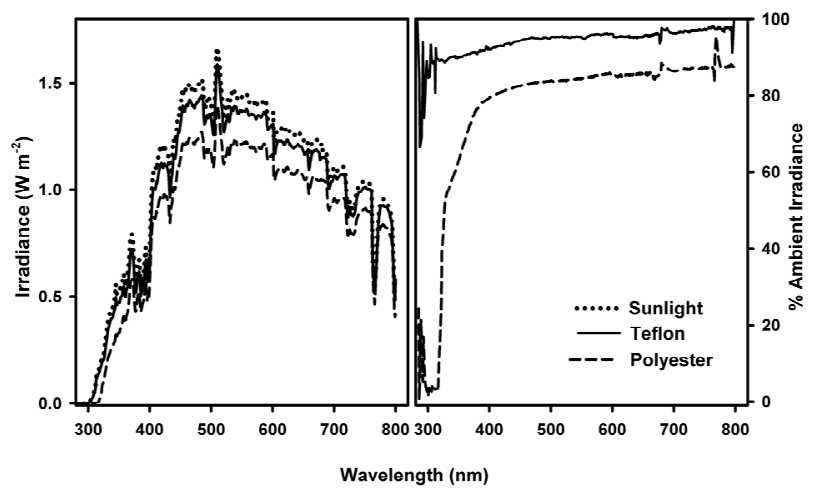

Figure 2. Spectral distribution (left) and attenuation (right) of direct sunlight by Teflon and Polyester covered exclusion shelters. Measurement of sunlight under shelters was made with an OL754 spectroradiometer at solar noon at summer solstice on a clear day with very high thin haze.

Leaf blades were removed from the petiole, the lengths along the midrib and widths of the central leaflet taken with a ruler and the leaf area $\left(\mathrm{cm}^{2}\right)$ determined using a LI-3000 portable area meter in the field. Disks were then taken from the central leaflet midway between the midrib and the margin placed in envelopes and dried for determination of specific leaf weight (SLW) or immediately transferred to $2 \mathrm{ml}$ polyethylene tubes on ice in the field and then held at $-80^{\circ}$ until pigment analysis could be performed. SLW was determined by carefully weighing the dried leaf disks and expressing the result as mass/unit area $\left(\mathrm{g} \cdot \mathrm{m}^{-2}\right)$. The remainder of each leaf was placed in envelopes and dried at $60^{\circ}$ for stable carbon isotope analysis.

\subsection{Pigment Analysis}

Soluble phenolic pigments were analyzed spectrophotometrically. Leaf disks (diameter $=1.35 \mathrm{~cm}$ ) were placed in $20 \mathrm{ml}$ high density polyethylene (HDPE) scintillation vials, covered with $10 \mathrm{ml}$ of slightly acidified aqueous methanol (MeOH: $\mathrm{H}_{2} \mathrm{O}: \mathrm{AcOOH}, 50: 50: 1$, v:v:v) delivered from a $100 \mathrm{ml}$ buret, tightly capped and held in the dark at room temperature with gentle agitation (50 rpm) for $48-72 \mathrm{hrs} \mathrm{[27].} \mathrm{To} \mathrm{insure} \mathrm{that} \mathrm{photosynthetic}$ pigments were not present in the phenolic extracts, the extract absorbance was determined from 260 to $760 \mathrm{~nm}$ at $1 \mathrm{~nm}$ intervals with a Shimadzu UV-1601 Spectrophotometer dual beam spectrophotometer. For presentation, data from 260 to $500 \mathrm{~nm}$ are shown.

\subsection{Gas Exchange and Stomatal Density}

Conductance measurements were made on both upper and lower leaf surfaces with a LI-1600 steady state porometer (Li-Cor Inc., Lincoln, NE) and logged to a computer. The evening prior to making measurements the plots were irrigated in an attempt to eliminate spatial and temporal variability and to ensure that any differ- ences noted did not result from mild water stress. Meas- urements were made on five individuals of each isoline from each shelter. Measurements were completed in two consecutive mornings on clear days about a week prior to anthesis. Each session began as soon as the dew was dried off the leaves and ended around solar noon. Three leaves from each isoline were selected from three exclusion shelters from each treatment for stomatal density determination. The stomatal density (stoma $\mathrm{mm}^{-2}$ ) of both adaxial and abaxial leaf surfaces was determined using cyanoacrylate leaf impressions made on glass slides [29]. Stoma were counted along transects midway between the midrib and leaf edge and parallel to the mid$\operatorname{rib}[30,31]$.

\subsection{Stable Carbon Isotope Analysis}

Dry leaf material remaining from cutting leaf disks for pigment analysis was passed through a 60 mesh screen, sealed in airtight polyethylene vials and held in the dark at room temperature until analysis could be done. For each sample, material from three plants were taken, mixed, and $2-3 \mathrm{mg}$ portions were placed in tin capsules. Hence, three samples from each cultivar under each shelter were analyzed. Samples were submitted for measurement of $\delta^{13} \mathrm{C}$ abundance ratios on a SIRA Series II mass spectrometer (Micromass, Manchester, UK) operated in automatic trapping mode after combustion of samples in an elemental analyzer (NA1500 Series 1, Carlo Erba Instrumentazion, Milan, Italy). Reference $\mathrm{CO}_{2}$ was calibrated against standard Pee Dee belemite (Ozteck, Dallas, TX). For presentation, data were converted from $\delta^{13} \mathrm{C}$ to $\Delta$, the stable carbon isotope fractionation resulting from the assimilation weighted intercellular $\mathrm{CO}_{2}$ concentration during the lifetime of the plant [32].

The whole above ground portion of the plant, both stems and leaves, were oven dried at and weighed to determine whole above ground biomass and subsequently 
processed as described above for stable carbon isotope analysis. Measurements were made on three individuals of each isoline from each shelter.

\section{Results}

One way ANOVA revealed no significant variation within like treatments, either Teflon or Mylar, so to simplify presentation, data were simply combined and analyzed using Student's t-test. The absorbance spectra of the extracts differed between the isolines (Figure 3). Extracts prepared from OX942 had maximal absorbance at $260 \mathrm{~nm}$ with a shoulder at $330 \mathrm{~nm}$, while the other isolines exhibited a more complex pattern with two peaks at 260 and $330 \mathrm{~nm}$ and a smaller peak, or a shoulder at $300 \mathrm{~nm}$.

Extract absorbance of plants grown under near ambient UV-B (Teflon) was higher in comparison to those from plants grown with UV exclusion (Mylar). In every line the increased absorbance was highly significant $(p<$ 0.001 , Student's t-test) at each wavelength within the UV-B and throughout much (to $400 \mathrm{~nm}$ ) of the UV-A waveband. Absorbance maxima characteristics of chloro-

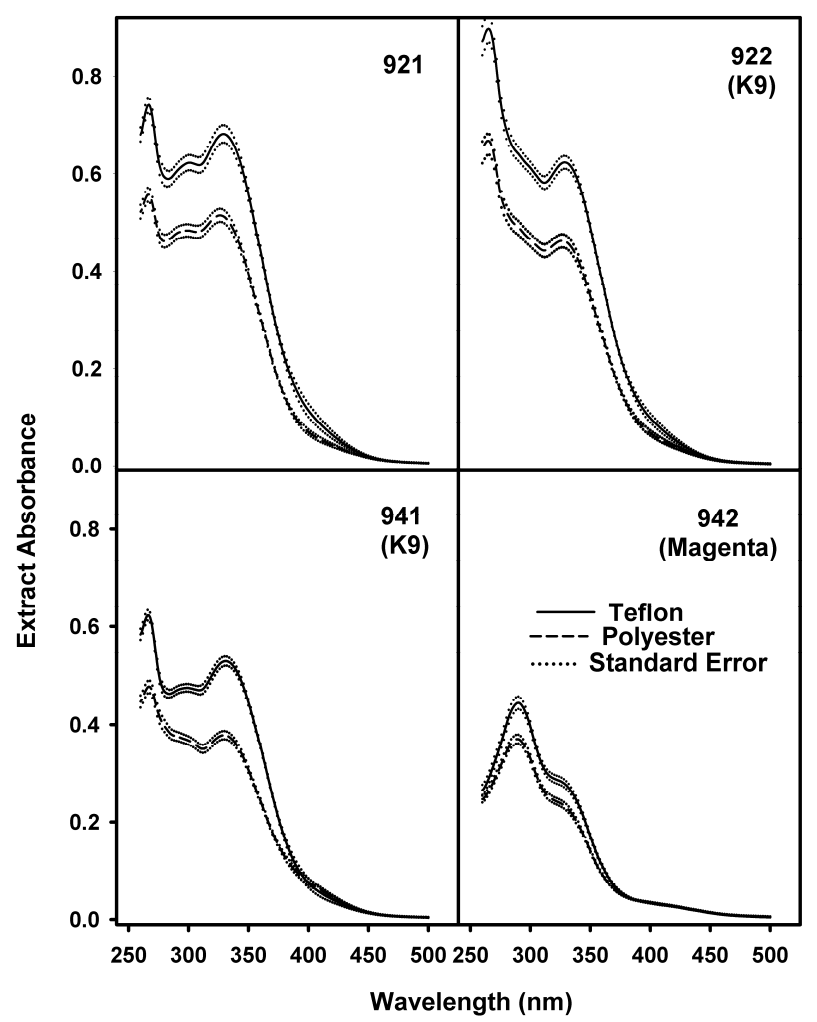

Figure 3. Mean absorbance of $50 \%$ aqueous methanolic leaf disk extracts from soybean plants grown with (shaded bars) and without (open bars) near-ambient solar UV-B. Values are means \pm S.E.. Extract absorbance in the UV-B waveband was significantly different $(p<0.001)$ between treatments in every isoline $(n=40)$. phylls and carotenoids were not detected. Carotenoids typically absorb as a triple peak or single peak flanked by two shoulders centered at about $450 \mathrm{~nm}$. Such features were absent from the absorbance spectra so the observed increase in absorbance was not influenced by inadvertent extraction of photosynthetic pigments and was due solely to extractible secondary phenols.

While mean leaf area (Figure 4(a)) was consistently reduced across isolines with UV-B, generally by $11 \%$ $13 \%$, the leaf area of OX921 was decreased by only $3.5 \%$ and was of practically no significance $\left(P_{t}=0.4\right)$. Conversely, OX921 exhibited the largest SLW increase of about $6.8 \%$ (Figure 4(c)). Leaf area reductions were apparently due to near isotropic reduction in leaf expansion within each isoline pair (Figure 4(b)), though there was considerable difference between sister isolines.

In general, changes in stomatal density (Figures 5(a) \&

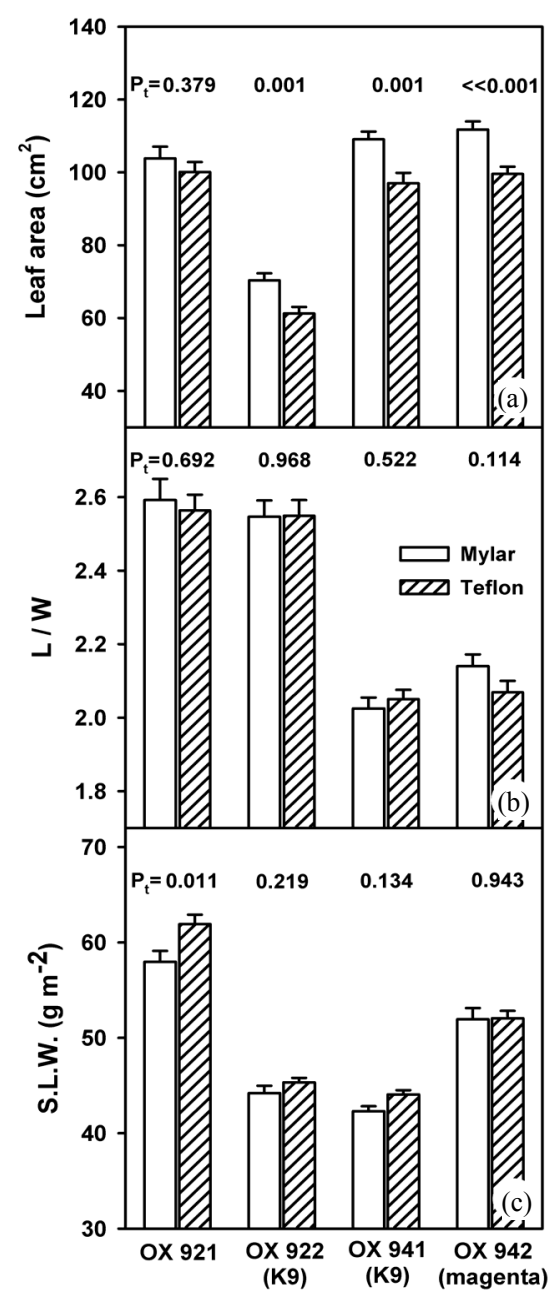

Figure 4. Response of selected leaf morphological parameters to growth with (shaded bars) and without (open bars) near-ambient solar UV-B. (a) Leaf area; (b) The ratio of leaf length to width and; (c) Specific leaf weight. Bars are means \pm S.E. Results of t-test $\left(P_{t}\right)$ are shown $(n=40)$. 
(b)) exhibited a pattern similar to stomatal conductance (Figures 5(c) \& (d)). Adaxial and abaxial stomatal density was depressed only in the K9 cultivars (OX922 \& OX941) by ambient UV-B (adaxial conductance of OX922 was not measurable). Stomatal density and conductance of the other isolines, OX921 and OX942, increased or exhibited little change. OX921 was most responsive to UV-B; stomatal density and conductance increased by about $15 \%$.

Stable carbon isotope discrimination $(\Delta)$ revealed similar trends (Figure 6) to stomatal responses. The almost exclusively hypostomatous OX922 and OX941 were the most responsive to ambient UV-B while OX921 and OX942 were relatively unchanged. Although effect upon $\Delta$ was less pronounced statistically, the mean response of leaf level and whole plant $\Delta$ were consistent with one another.

While the response of shoot biomass (Figure 7) was of modest significance except in the case of OX921, the mean magnitudes of these values and their responses are of a pattern remarkably consistent with those of both the stomatal and stable carbon isotope results.

\section{Discussion}

In the study described here, two pairs of sister isolines were selected: OX921 \& OX922 and OX941 \& OX942 $[33,34]$. Their phenotypic characteristics are summarized in Table 1. These isolines were selected for contrasting flavonoid composition, stomatal distributions, and the differential response of stomatal development to blue light and UV-B radiation [31]. Within each pair the soybean isolines differ by a single gene, based upon phenotypic segregation in breeding experiments [35].

The OX921 and OX922 isoline pair was selected to correspond with previous studies [27,31]. OX922 is almost entirely hypostomatous, exhibits reduced chlorophyll content and photosynthetic rate, and produces a kaempferol glycoside with a uniquely branched tri-glucosyl side chain, K9 (kaempferol-3-O-2 ${ }^{\mathrm{G}}$-gentiobioside). Its sister, OX921, is amphistomatous and produces a normal complement of kaempferol glycosides, predominately K6 (kaempferol-3-O-sophoroside). Stomatal de-

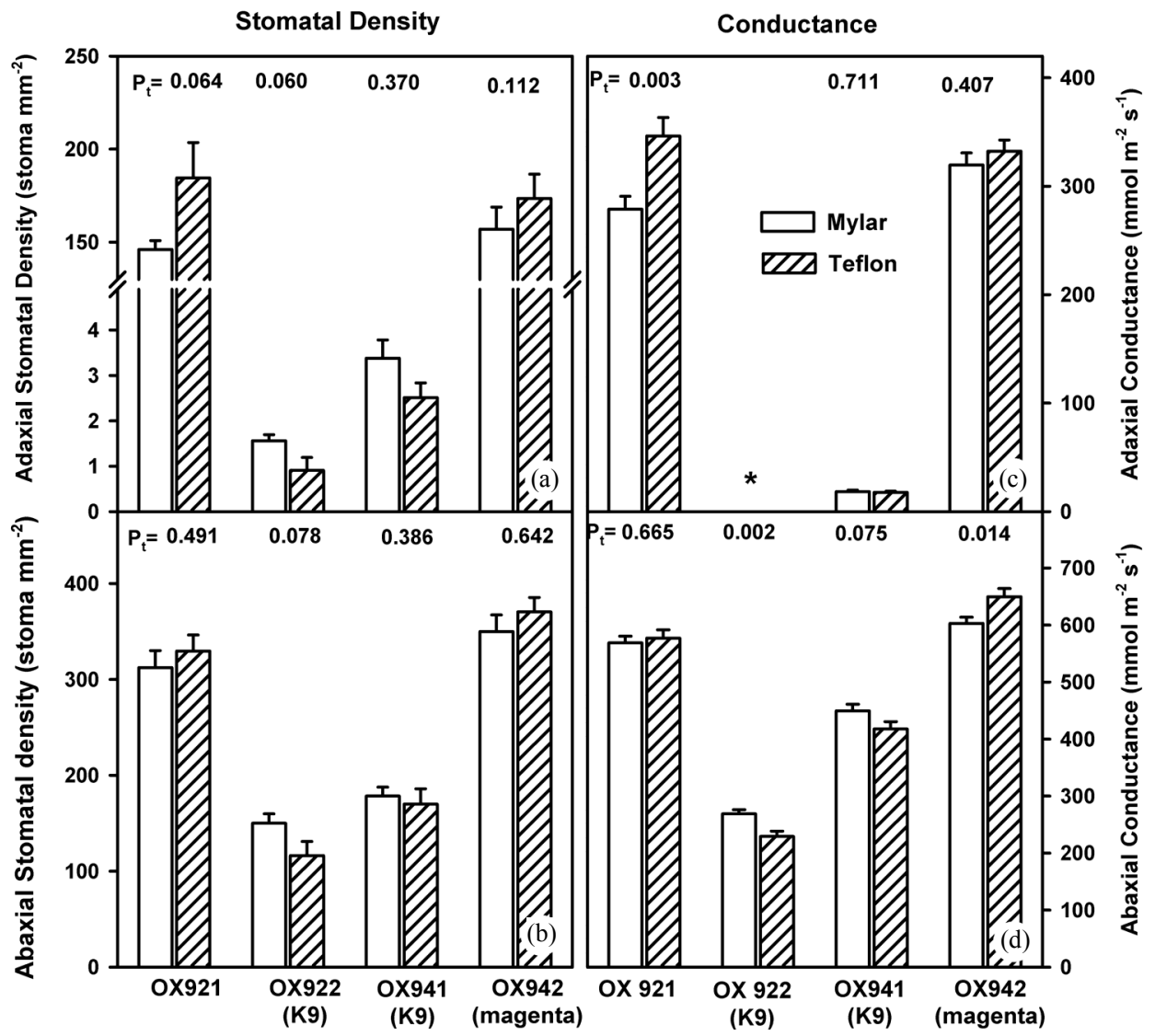

Figure 5. Stomatal density and conductance in soybean leaves grown with (shaded bars) and without (open bars) supplemental UV-B radiation. Left: Adaxial (upper graph, (a)) and abaxial (lower graph, (b)) stomatal density of soybean leaves. Results of two-tailed (student's) t-test are shown. Right: Adaxial (upper, (c)) and abaxial (lower, (d)) stomatal conductance. Adaxial stomatal conductance of OX922 was not measurable with available instrumentation. In each case bars are means \pm S.E. and results of Student's t-test $\left(\mathbf{P}_{\mathbf{t}}\right)$ are shown $(n=20)$. 


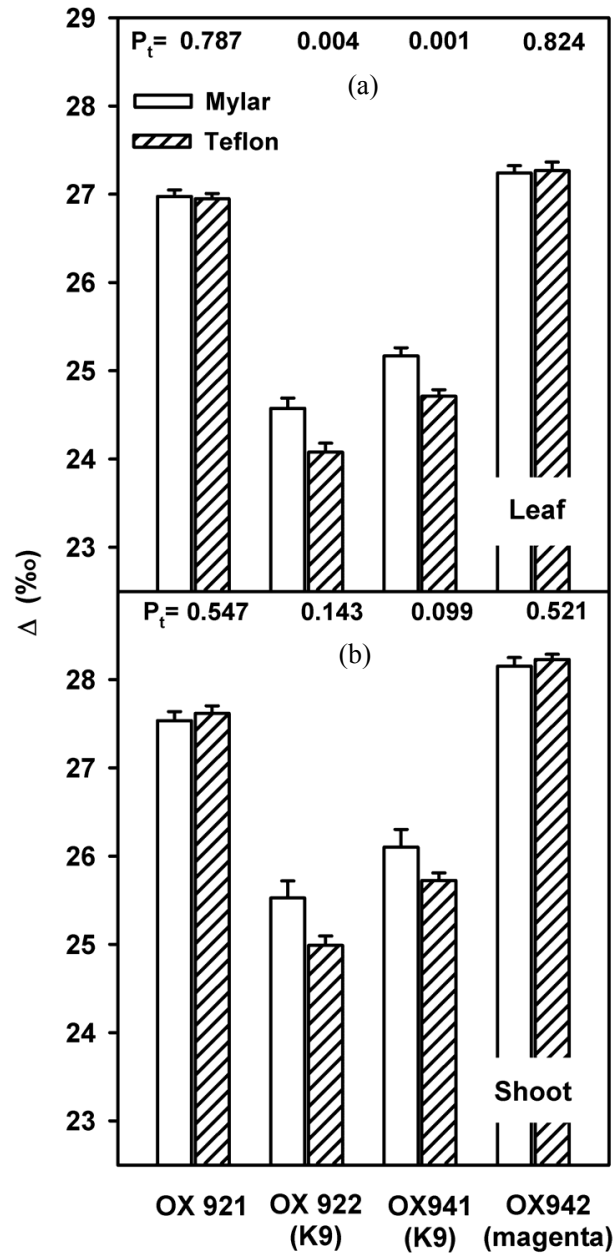

Figure 6. Stable carbon isotope discrimination of soybean leaves (a) and soybean plants (b) grown with (shaded bars) or without (open bars) near-ambient solar UV-B. Bars are means \pm S.E. Results of $t$-test are shown $(n=12)$.

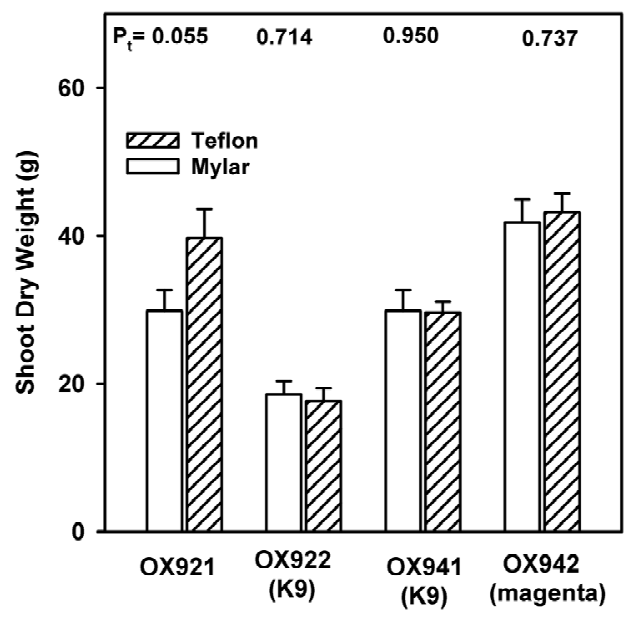

Figure 7. End of season plant biomass accretion as shoot dry weight of soybean grown with (shaded bars) or without (open bars) near-ambient solar UV-B. Bars are means \pm S.E. Results of t-test $\left(P_{t}\right)$ are shown $(n=12)$. velopment in OX922 is inhibited by blue light and the response does not involve phytochrome [31]. The hypothesis that $\mathrm{K} 9$ somehow directly inhibits stomatal formation in soybean [34] remains standing.

Similarly, OX941 \& OX942 were included because of differences in stomatal distribution, blue light sensitivity, and the hypothesized involvement of K9 (Table 1). OX941 is a hypostomatous K9 producer while OX942 is amphistomatous and produces only trace amounts of flavonols. This was of particular interest since it is generally recognized that a primary adaptive advantage conferred by epidermal flavonoids is UV-B stress tolerance by screening out ultraviolet radiation before it reaches underlying sensitive photosynthetic tissues.

Increased phenolic synthesis and accumulation are consistently reported plant responses to UV-B radiation. To evaluate the potential for induction of the suite of UV photomorphogenic responses in the experimental system we examined levels of the extractible soluble phenolics. In soybean, blue/UV radiation elicits photomorphogenic responses such as altered stomatal density [31], reduced leaf and shoot expansion [17] and increased leaf thickness [36]. Evidence has continued to accumulate that similar or in some cases identical photoreceptors are involved allowing plants to respond to blue/UV both architecturally and chemically (e.g. [15,37-39]). Moreover, the preceding illustrates the view that while pigment accumulation in general might not constitute a morphological characteristic in stricta, the specific case of secondary phenolic accumulation in response to UV-B might accurately be considered a photomorphogenic response [15].

The phenolic responses presented here are consistent with those obtained in similar field studies in which ambient UV-B was selectively removed by growth under cutoff filters $[26,40]$ and in experiments where glasshouse grown OX921 \& OX922 were grown under enhanced UV-B [27]. If such increases in phenolic pigments were elicited through mechanisms similar to that of architectural responses [39], then one might view phenolic accumulation as a surrogate measure for the potential induction of an entire suite of putative UV photomorphogenic responses. The morphological responses observed in the present study are consistent with this. These are well established responses of soybean to enhanced UV-B. Taken together, this suggests that ambient UV-B radiation has the potential to act as photomorphogenic signal.

It is a long standing hypothesis that a primary adaptive advantage conferred by leaf epidermal flavonoids is the attenuation of potentially harmful UV-B radiation prior to reaching sensitive photosynthetically active mesophyll [41]. Flavonols are generally thought to be 
Table 1. Stomatal density and flavonol glycoside expression associated with soybean isoline pairs [27,31,33,34].

\begin{tabular}{|c|c|c|c|c|c|}
\hline \multicolumn{2}{|c|}{ Isoline Pair } & OX921 & OX922 & OX941 & OX942 \\
\hline \multicolumn{2}{|c|}{ Genotype } & $f g 1 \mathrm{fg} 2 \mathrm{Fg} 3 \mathrm{Fg} 4$ & $\mathrm{Fg} 1 \mathrm{fg} 2 \mathrm{Fg} 3 \mathrm{Fg} 4$ & $\mathrm{Fg} 1 \mathrm{Fg} 3 \mathrm{Wm}$ & $\mathrm{Fg} 1 \mathrm{Fg} 3 \mathrm{wm}$ \\
\hline \multicolumn{2}{|c|}{ Predominant Flavonol } & $\begin{array}{l}\text { K6, kaempferol } \\
\text { diglycoside }\end{array}$ & $\begin{array}{l}\text { K9, a branched kaemp- } \\
\text { ferol triglycoside }\end{array}$ & $\begin{array}{l}\text { K9, a branched kaemp- } \\
\text { ferol triglycoside }\end{array}$ & $\begin{array}{l}\text { "magenta" isoline, } \\
\text { only trace flavonols }\end{array}$ \\
\hline \multicolumn{2}{|c|}{ Flavonol Content $\left(\mu \mathrm{g} \cdot \mathrm{cm}^{-2}\right)$} & 58 & 50 & 45 & 1.7 \\
\hline \multirow{2}{*}{ Stomatal Density $\left(\mathrm{mm}^{-2}\right)$} & Upper & 164 & 5 & 3 & 146 \\
\hline & Lower & 303 & 241 & 141 & 319 \\
\hline
\end{tabular}

responsible for the bulk of UV-B inducible pigment expression. Hydroxycinnamic acids (HCAs) have also been shown to effectively screen UV-B within the leaves of soybean [39] and other plants [42]. In the present study, the maximal absorption of all the all extracts was around $330 \mathrm{~nm}$ or shorter wavelengths, consistent with HCAs being the predominate UV absorbing compounds in the extracts [43]. HCA synthesis has been found to be UV-B inducible, although flavonol induction is specifically or preferentially enhanced by UV-B radiation in a wide range of plants $[44,45]$. The OX942 isoline, which was blocked in flavonol synthesis, exhibited increased leaf extract absorbance with UV-B and it seems likely that photosynthesis was unaffected since biomass was unchanged. We conclude that while flavonols may function as efficient UV screening pigments, they are not a prerequisite for UV-B tolerance in soybean.

An earlier report described the morphological and physiological responses of the OX921/OX922 isoline pair to UV-B [27]. Consistent with the present study, it was reported that OX922, the K9 isoline, was much more responsive than its sister isoline under glasshouse conditions and most other results are comparable. However, one difference between the two studies is notable. In the greenhouse study adaxial stomatal density was depressed with UV-B whereas in the present study it increased (response of abaxial stomatal densities were comparable). It has been well documented that under low levels of photosynthetically active radiation, plants are much more responsive to or easily damaged by UV. It remains a possibility that the observed reductions in stomatal density in greenhouse experiments are the result of UV damage to developing stomatal initials rather than the result of a true photomorphogenic process, especially with regard to the upper leaf surface. As with the previous study, regardless of whether a damage or photomorphogenic response is involved, conductance generally exhibited a response pattern to UV-B similar to that of stomatal density. A generalized inhibition of epidermal cell division by UV has also been reported in greenhouse grown pea, although this did not result in reduced stomatal densities owing to reduced leaf area [24]. A reduction in stomatal density in response to putatively non-damaging blue light during leaf development was reported in OX922, caused by arrested stomatal development primarily at the guard mother cell stage [31].

\section{Conclusion}

Stomatal density, conductance, biomass, and WUE as $\Delta$ all exhibited nearly identical responses to UV-B treatment, consistent with the notion of a photomorphogenic response leading to altered WUE. Taken together, the results indicate that UV-B photomorphogenic processes could affect soybean WUE under agronomically relevant ambient light, but such effects are cultivar dependent. Although this study does not eliminate the role that other photomorphogenic responses might play in affecting gas exchange in soybean, it does point to the potential for such mechanisms in field grown plants.

\section{Acknowledgements}

We thank Dr. Lan Liu-Gitz for helpful discussions and suggestions through the course of this experiment and Roman Mirecki for his technical assistance.

\section{REFERENCES}

[1] J. G. Anderson, D. W. Toohey and W. H. Brune, "Free Radicals within the Antarctic Vortex: The Role of CFC's in Antarctic Ozone Loss," Science, Vol. 251, No. 4989, 1991, pp. 39-46. http://dx.doi.org/10.1126/science.251.4989.39

[2] M. P. McCormick, L. W. Thomason and C. R. Trepte, "Atmospheric Effects of the Mt. Penatubo Eruption," Nature, Vol. 373, 1995, pp. 399-404. http://dx.doi.org/10.1126/science.251.4989.39

[3] T. A. Day and P. J. Neale, "Effects of UV-B Radiation on Terrestrial and Aquatic Primary Producers," Annual Review of Ecology and Systematics, Vol. 33, 2002, pp. 371396.

http://dx.doi.org/10.1146/annurev.ecolsys.33.010802.150 $\underline{434}$

[4] M. Tevini, "Physiological Changes in Plants Related to 
UV-B Radiation: An Overview," In: R. H. Biggs and M. E. B. Joyner, Eds., Stratospheric Ozone Depletion/UV-B Radiation in the Biosphere, NATO ASI Series I: Global Environmental Change, Vol. 18, Springer Verlag, New York, 1994, pp. 37-56. http://dx.doi.org/10.1007/978-3-642-78884-0 6

[5] P. A. Ensminger, "Control of Development in Plants and Fungi by Far-UV Radiation," Physiologia Plantarum, Vol. 88, No. 3, 1993, pp. 501-508. http://dx.doi.org/10.1111/j.1399-3054.1993.tb01365.x

[6] A. H. Teramura, "Effects of UV-B Radiation on the Growth and Yield of Crop Plants," Physiologia Plantarum, Vol. 58, No. 3, 1983, pp. 415-427. http://dx.doi.org/10.1111/j.1399-3054.1983.tb04203.x

[7] W. G. Gold and M. M. Caldwell, "The Effects of Ultraviolet-B Radiation on Plant Competition in Terrestrial Ecosystems," Physiologia Plantarum, Vol. 58, No. 3, 1983, pp. 435-444. http://dx.doi.org/10.1111/j.1399-3054.1983.tb04205.x

[8] P. W. Barnes, C. L. Ballaré and M. M. Caldwell, "Photomorphogenic Effects of UV-B Radiation on Plants: Consequences for Light Competition," Journal of Plant Physiology, Vol. 148, No. 1-2, 1996, pp. 15-20. http://dx.doi.org/10.1016/S0176-1617(96)80288-4

[9] J. H. Sullivan, "Effects of Increasing UV-B Radiation and Atmospheric Carbon Dioxide on Photosynthesis and Growth: Implications for Terrestrial Ecosystems," Plant Ecology, Vol. 128, No. 1-2, 1997, pp. 195-206. http://dx.doi.org/10.1023/A:1009790424214

[10] M. M. Caldwell, "Solar UV Radiation and the Growth and Development of Higher Plants," In: A. C. Griese, Ed., Photophysiology, Vol. 6, Academic Press, New York, 1971, pp. 137-171. http://dx.doi.org/10.1016/B978-0-12-282606-1.50010-6

[11] M. Tevini and A. H. Teramura, "UV-B Effects on Terrestrial Plants," Photochemistry and Photobiology, Vol. 50, No. 4, 1971, pp. 479-487. http://dx.doi.org/10.1111/j.1751-1097.1989.tb05552.x

[12] G. I. Jenkins, "Signal Transduction in Responses to UV-B Radiation," Annual Review of Plant Biology, Vol. 60, 2009, pp. 407-431. http://dx.doi.org/10.1146/annurev.arplant.59.032607.0929 $\underline{53}$

[13] H. Bandurska, J. Niedziela and T. Chadzinikolau, "Separate and Combined Responses to Water Deficit and UV-B Radiation," Plant Science, Vol. 213, 2013, pp. 98-105. http://dx.doi.org/10.1016/j.plantsci.2013.09.003

[14] H. K. Lichtenthaler, "Vegetation Stress: An Introduction to the Stress Concept in Plants," Journal of Plant Physiology, Vol. 148, No. 1-2, 1996, pp. 4-14. http://dx.doi.org/10.1016/S0176-1617(96)80287-2

[15] C. J. Beggs and E. Wellman, "Photocontrol of Flavonoid Synthesis," In: R. E. Kendrick and G. H. M. Kronenberg, Eds., Photomorphogenesis in Plants, 2nd Edition, Kluwer Academic Publishers, Boston, 1994, pp. 733-751. http://dx.doi.org/10.1007/978-94-011-1884-2_26

[16] D. C. Gitz III and L. Liu-Gitz, "How Do UV Photomorphogenic Responses Confer Water Stress Tolerance?"
Photochemistry and Photobiology, Vol. 78, No. 6, 2003, pp. 529-524.

http://dx.doi.org/10.1562/0031-8655(2003)078<0529:HD $\underline{\mathrm{UPRC}}>2.0 . \mathrm{CO} ; 2$

[17] J. H. Sullivan and A. H. Teramura, "Field Study of the Interaction of between Solar Ultraviolet-B Radiation and Drought on Photosynthesis and Growth in Soybean," Plant Physiology, Vol. 92, No. 1, 1990, pp. 141-146. http://dx.doi.org/10.1104/pp.92.1.141

[18] A. H. Teramura, J. H. Sullivan and L. H. Ziska, "Interaction of Elevated Ultraviolet-B Radiation and $\mathrm{CO}_{2}$ on Productivity and Photosynthetic Characteristics in Wheat, Rice, and Soybean," Plant Physiology, Vol. 94, No. 2, 1990, pp. 470-475. http://dx.doi.org/10.1104/pp.94.2.470

[19] E. M. Middleton and A. H. Teramura, "The Role of Flavanol Glycosides and Carotenoids in Protecting Soybean from Ultraviolet-B Damage," Plant Physiology, Vol. 103, No. 94, 1993, pp. 741-752.

[20] Q.-J. Dai, S.-B. Peng, A. Q. Chavez and B. S. Vergara, "Effects of UVB Radiation on Stomatal Density and Opening in Rice (Oryza sativa L.)," Annals of Botany, Vol. 76, No. 1, 1995, pp. 65-70. http://dx.doi.org/10.1006/anbo.1995.1079

[21] D. J. Allen, S. Nogués and N. R. Baker, "Ozone Depletion and Increased Ultraviolet-B Radiation; Is There a Threat to Photosynthesis?" Journal of Experimental Botany, Vol. 49, No. 328, 1998, pp. 1775-1778.

[22] S. Nogués, D. J. Allen, J. I. L. Morison and N. R. Baker, "Ultraviolet-B Radiation Effects on Water Relations, Leaf Development, and Photosynthesis in Droughted Pea Plants," Plant Physiology, Vol. 117, No. 1, 1998, pp. 173-181. http://dx.doi.org/10.1104/pp.117.1.173

[23] S. Nogués, D. J. Allen, J. I. L. Morison and N. R. Baker, "Characterization of Stomatal Closure Caused by Ultraviolet-B Radiation," Plant Physiology, Vol. 121, No. 2, 1999, pp. 489-496. http://dx.doi.org/10.1104/pp.121.2.489

[24] S. Nogués and N. R. Baker, "Effects of Drought on Photosynthesis in Mediterranean Plants Grown under Enhanced UV-B Radiation," Journal of Experimental Botany, Vol. 51, No. 348, 2000, pp. 1309-1317. http://dx.doi.org/10.1093/jexbot/51.348.1309

[25] N. Feng, L. An, T. Chen, W. Qiang, S. Xu, M. Zhang, M. Wang and G. Cheng, "The Effect of Enhanced Ultraviolet-B Radiation on Growth, Photosynthesis and Stable Carbon Isotope Composition $\left(\delta^{13} \mathrm{C}\right)$ of Two Soybean Cultivars (Glycine max) under Field Conditions," Environmental and Experimental Botany, Vol. 49, No. 1, 2003, pp. 1-8. http://dx.doi.org/10.1016/S0098-8472(02)00043-6

[26] M. A. Schumaker, J. H. Bassman, R. Robberecht and G. K. Radamaker, "Growth, Leaf Anatomy, and Physiology of Populus Clones in Response to Solar Ultraviolet-B Radiation," Tree Physiology, Vol. 17, No. 10, 1997, pp. 617-626. http://dx.doi.org/10.1093/treephys/17.10.617

[27] D. C. Gitz III, L. Liu-Gitz, S. J. Britz and J. H. Sullivan, "Ultraviolet-B Effects on Stomatal Density, Water-Use Efficiency, and Stable Carbon Isotope Discrimination in 
Four Glasshouse-Grown Soybean (Glycine max) Cultivars," Environmental and Experimental Botany, Vol. 53, No. 3, 2004, pp. 343-355.

http://dx.doi.org/10.1016/j.envexpbot.2004.04.005

[28] M. M. Caldwell, S. D. Flint and P. S. Searles, "Spectral Balance and UV Sensitivity of Soybean: A Field Experiment," Plant Cell and Environment, Vol. 17, No. 3, 1994, pp. 267-276.

http://dx.doi.org/10.1111/j.1365-3040.1994.tb00292.x

[29] C. L. Wilson, W. P. Pusey and B. E. Otto, "Plant Epidermal Sections and Imprints Using Cyanoacrylate Adhesives," Canadian Journal of Plant Science, Vol. 61, 1986, pp. 781-782. http://dx.doi.org/10.4141/cjps81-117

[30] D. C. Gitz III, "Effect of UV-B Radiation on Photosynthesis and Growth of Two Soybean Cultivars," Master's Thesis, Miami University, Oxford, 1993.

[31] L. Liu-Gitz, S. J. Britz and W. P. Wergin, "Blue Light Inhibits Stomatal Development in Soybean Isolines Containing Kaempferol 3-O-2 ${ }^{\mathrm{G}}$-Glycosyl-Gentiobioside (K9), a Unique Flavonoid Glycoside," Plant Cell and Environment, Vol. 23, No. 8, 2000, pp. 883-891.

http://dx.doi.org/10.1046/j.1365-3040.2000.00608.x

[32] G. D. Farquhar, J. R. Ehleringer and K. T. Hubick, "Carbon Isotope Discrimination and Photosynthesis," Annual Review of Plant Physiology and Plant Molecular Biology, Vol. 40, 1989, pp. 503-547. http://dx.doi.org/10.1146/annurev.pp.40.060189.002443

[33] B. R. Buttery and R. I. Buzzell, "Varietal Differences in Leaf Flavonoids of Soybean," Crop Science, Vol. 13, No. 1, 1973, pp. 103-106.

[34] B. R. Buttery and R. I. Buzzell, "Leaf Traits Associated with Flavonol Glycoside Genes in Soybean," Plant Physiology, Vol. 85, No. 1, 1987, pp. 20-21. http://dx.doi.org/10.1104/pp.85.1.20

[35] B. R. Buttery and R. I. Buzzell, "Relationships among Photosynthetic Rate, Bean Yield and Other Characters in Field-Grown Cultivars of Soybean," Canadian Journal of Plant Science, Vol. 61, No. 2, 1981, pp. 191-198. http://dx.doi.org/10.4141/cjps81-029

[36] N. S. Murali and A. H. Teramura, "Effectiveness of UVB Radiation on the Growth and Physiology of Field Grown Soybean Modified by Water Stress," Photochemistry and Photobiology, Vol. 44, No. 2, 1986, pp. 215219. http://dx.doi.org/10.1111/j.1751-1097.1986.tb03588.x

[37] C. Ballaré, A. L. Scopel, R. A. Sanchez and S. R. Radosevich, "Photomorphogenic Processes in the Agricultural Environment," Photochemistry and Photobiology, Vol. 56, No. 5, 1992, pp. 777-788. http://dx.doi.org/10.1111/j.1751-1097.1992.tb02234.x

[38] W. R. Briggs, and E. Huala, "Blue-Light Photoreceptors in Higher Plants," Annual Review of Cell and Developmental Biology, Vol. 15, 1999, pp. 33-62.

http://dx.doi.org/10.1146/annurev.cellbio.15.1.33

[39] M. Heijde and R. Ulm, "UV-B Photoreceptor-Mediated Signalling in Plants," Trends in Plant Science, Vol. 17, No. 4, 2012, pp. 230-237. http://dx.doi.org/10.1016/j.tplants.2012.01.007

[40] C. A. Mazza, H. E. Boccalandro, C. V. Giordano, D. Battista, A. L. Scopel and C. L. Ballaré, "Functional Significance and Induction by Solar Radiation of UltravioletAbsorbing Sunscreens in Field-Grown Soybean Crops," Physiologia Plantarum, Vol. 122, No. 1, 2000, pp. 117126. http://dx.doi.org/10.1104/pp.122.1.117

[41] J. W. McClure, "Physiology of Phenolic Compounds in Plants," In: C. F. Van Sumere, T. Swain and J. B. Harborne, Eds., Recent Advances in Phytochemistry, Vol. 12, The Biochemistry of Plant Phenolics, Plenum Publishing Corp., New York, 1979, pp. 525-555.

[42] J. J. Sheahan, "Sinapate Esters Provide Greater UV-B Attenuation Than Flavonoids in Arabidopsis Thaliana (Brassicaceae)," American Journal of Botany, Vol. 83, No. 6, 1996, pp. 679-686. http://dx.doi.org/10.2307/2445845

[43] T. Swain, "Flavonoids," In: T. W. Goodwin, Ed., Chemistry and Biochemistry of Plant Pigments, 1976, pp. 166206.

[44] L. Liu, D. C. Gitz III and J. W. McClure, "Effects of UV-B on Flavonoids, Ferulic Acid, Growth, and Photosynthesis in Barley Primary Leaves," Physiologia Plantarum, Vol. 93, No. 4, 1995, pp. 725-733. http://dx.doi.org/10.1111/j.1399-3054.1995.tb05123.x

[45] S. Reuber, J. F. Bornman, and G. Weissenböck, "Phenylpropanoid Compounds in Primary Leaf Tissues of Rye (Secale cereale): Light Response of Their Metabolism and the Possible Role in UV-B Protection," Physiologia Plantarum, Vol. 97, No. 1, 1996, pp. 160-168. http://dx.doi.org/10.1111/j.1399-3054.1996.tb00492.x 